\title{
TOURISM-BASED APPROACH TO CONSERVING THE BUILT HERITAGE SITES IN THE HOLY CITY OF MAKKAH, SAUDI ARABIA
}

\author{
MOHAMMED BAGADER \\ Islamic Architecture Department, Umm Al-Qura University, Saudi Arabia
}

\begin{abstract}
Conserving built heritage is one of the indications of a nations' pride, development and sophistication. Besides, tourism becomes an essential tool to ensure conserving built heritage sites in order to maintain their physical condition, as well as to promote them for economic vitality. Many developed and developing countries use heritage sites as an economic source for tourism destination attractions; however, the Holy city of Makkah (Mecca) in Saudi Arabia is considered as Muslims' most important city ever, which still has some built heritage sites that still exist now, due to a reasonable reason (expansion to accommodate an enormous number of pilgrims). More than 3 million pilgrims visit Makkah annually, eager to perform religious practices. Some of them visit at least some of the existing heritage sites or go to see the remnants of them. These sites are either architectural monuments (such as the palaces of Kuwair and King Saud), old markets where trade is still practiced (such as the Jaroul market), old mosques (such as Al-Baya'a Mosque in Mina), or sites related to religious occasions such as Ghar Hira'a (Hira'a Cave). These built heritage sites are some of the last remaining memories of Makkah, and many experts stress the importance of preserving and re-using them, which aligns with the Kingdom's Vision 2030. This paper aims to propose an approach to conserving the built heritage remaining in Makkah, by using tourism as a driving tool. This paper uses a qualitative method by conducting a systematic literature review and presenting one case study of Kuwair Palace (built in 1370 $\mathrm{AH} / 1951 \mathrm{AD})$.
\end{abstract}

Keywords: built heritage, conservation, heritage sites, Kuwair Palace, Mecca, Muslim pilgrimage, Saudi Arabia, tourism, urban planning.

\section{INTRODUCTION}

Built heritage is one of the essential components and evidence of human evolution throughout history; it reflects the capabilities that people have reached in overcoming their surrounding environment [1]. The conservation of built heritage is considered a measure of the progress and development of nations, due to its factual and moral impacts, which affect cultural, social and economic levels [2]. Heritage is defined as a precious (material or intellectual) property that is inherited from one generation to another, because of its importance in both continuity and growth, as heritage is a symbolic resource that is closely related to the issue of collective memory and identity [3].

Built heritage has many images, and is divided into two types: tangible and intangible, with the tangible being constructions such as monuments, castles, mosques, and other sites. As for the intangible built heritage, it is like poetry, folklore, fairy tales, others [4]. This research focuses on tangible heritage, because of its apparent impact on the development of the urban, cultural and natural landscape, which will thus, lead toward preserving the intangible heritage spontaneously.

The concepts surrounding conserving the built heritage have evolved several times throughout history since the developed, and some developing countries, began to look at built heritage as a source of tourism and an investment tool that one can rely upon as an economic resource [5]. Additionally, these concepts require a clear vision based on multidimensional studies and many procedures. There are different approaches for the conservation of built 
heritage that depend on the primary goal of the conservation process, such as what tools were used, the methods of preservation, and a new type of use if it is changed [6].

Tourism became one of the main goals and methods used worldwide in order to enhance the built heritage sites and ensure their continuity. This paper attempts to develop an approach to conserve the remaining built heritage of Makkah via the use of tourism as a tool. Moreover, the built heritage in Makkah has suffered in the past few decades from the loss of its authenticity and identity, and very few heritage sites remain, some of which are still in their original states, yet suffering from severe degradation. Therefore, these sites need more attention in order to preserve, renovate and rehabilitate what remains. They remain steadfast and challenging to the rapidly evolving conditions, with all the requirements of modern lifestyles.

\section{METHODOLOGY}

The research is descriptive, and a qualitative approach has been taken to understand the fundamental issues involved in built heritage and tourism as development tools. The author has reviewed and analyzed many published works in the area of heritage conservation and its relationship to tourism. The thematic and content analyses were also used to scrutinize and infer the data acquired from report reviews and experts' responses. Besides, the researcher visited many heritage sites in Makkah, to gain practical experience regarding their current physical conditions. Finally, one built heritage site in Makkah was chosen as a case study, Kuwair Palace.

\section{TOURISM AS TOOL FOR BUILT HERITAGE CONSERVATION}

Tourism is a phenomenon of the twentieth century [7] that means there must be advanced forms of paid hospitality, which has various new and advanced styles in order to serve visiting guests well [8]. The World Tourism Organization defines tourism as: "takes full account of its current and future economic, social and environmental impacts, addressing the needs of visitors, the industry, the environment and host communities" [9]. This part of the paper is a literature review about the heathenship between heritage and tourism, and about how tourism can become a tool to conserve built heritage sites.

\subsection{The concepts of heritage and tourism}

As mentioned earlier, heritage means the passing on of the civilizations of predecessors back, and this is not limited to language, literature and customs; but includes all the physical and emotional elements of society, such as philosophy, religion, science, art and urbanism [2]. Additionally, heritage is a controversial concept, because it exposes significant roles in any society, such as regional history, local identity, a destination for tourism industry, and the developing society economically, culturally and socially [10]. Graham and Howard [11] defined specific roles for the concept of heritage, based on the purpose of conserving heritage, which can be either reclaiming the national/local identity or for industrial purposes, namely tourism. However, tourism is a unique opportunity for economic development changes in lifestyle [12]. It also provides cultural vitality and can support the preservation and conservation of heritage [13].

Orbaşli [14] said "Making tourism work for historic towns and their conservation depends foremost on the objectives of development and the authority to control it". Sustainable development of the built heritage conservation approach requires realistic planning that guarantees the direct benefits of local interests and local economies [15]. 


\subsection{The notion of tourism heritage}

The National Trust [16] defines heritage tourism as "traveling to experience the places, artifacts, and activities that authentically represent the stories and people of the past and present. It includes cultural, historic and natural resources". Another definition of tourism heritage is that the sustainable tourism activity that is aligned to tangible or intangible heritage [17]. Orbaşli and Woodward [18] consider heritage tourism and heritage conservation to be inherently linked. They also argue that the economic benefits of tourism are undeniable. Since the cultural environment adds value to the visitor experience, it becomes the reason for many destinations to conserve, manage and promote their heritage.

\subsection{Tourism and its relevance to the concept of built heritage conservation}

Tourism and built heritage conservation have many connections, like their impacts (positive and negative) on the heritage sites in terms of culture, economical, and more. Furthermore, tourism has its visible, tangible outcomes; such as job creation, tax revenues, as well as, its hidden tangible outcomes such as upgrading the quality of life [19]. It has a variety of attractions and types including religious tourism, arts tourism, cultural and heritage tourism, destination tourism, fairs, events and conferences, sports teams, recreation, and more. The World Tourism Organization Charter for sustainable tourism indicates that international tourism is the world's largest source of exports, and it is an essential factor in the balance of payments in many developed and developing countries [20]; however, both built heritage conservation and tourism have economic and social implications at different levels, not only for urban areas and architecture [21]. Culture is a crucial part of city life that dynamically develops within its community, in linking the past, present and future [15]. Rogers [22] says "we must realize that maintaining structures means maintaining the desirability or continuity of a culture - we are in fact conserving culture, not buildings".

The above was the most positive impact of the linkage between tourism and built heritage conservation; on the other hand, their relationship can also have negative impacts. For instance, Rothman [23] claims tourism is the "devil's bargain". He also argues that tourism "triggers a contest for the soul of a place", and it changes a place in unexpected and uncontrollable ways, destroying the originality of its culture and turning it into a prior touristic idea of the authentic culture of that place. Consequently, the success of the place as a tourist destination brings strangers to this place in unprecedented numbers, but their presence tends to destroy the heritage that made the place unique [24]. Venice is one of the most notable examples, where the residents became strangers, due to the large number of visitors [25].

To sum this up, the relationship between built heritage conservation and tourism is considered to be a complex one. The literature on heritage preservation and tourism distinguishes tourism that affects people and the places in which it occurs; and through it, it affects the tourists' experiences. This impact poses a challenge to efforts to conserve cultural heritage. The influence of tourism can either support or threaten built heritage conservation; however, there is a wide range of possible scenarios between these two concepts, in terms of outcomes.

\section{TOURISM APPROACH TO CONSERVE BUILT HERITAGE SITES}

This paper presents two examples of methods of strategies for conserving built heritage sites, through the adoption of developing tourism as an aspect of developing cities economically and culturally in several countries in the world, and in how to use a tourism-based approach to conserve built heritage sites, as follows. 


\subsection{Barcelona, Spain: Gaudi’s works}

The Catalan city of Barcelona is proud of its famous architect, Anthony Gaudi (1852-1926), as his timeless architectural works cover the city (more than 15 sites) between residential buildings, churches and a vast garden. The works of Gaudi are one of the examples of a picturesque Gothic Catalan architecture in the province of Catalonia. In 2017, more than 9 million tourists visited Barcelona, and 10 sites have been identified as the most visited tourist attractions [26]. Four out of ten sites (40\%) were Gaudi works within the city urban fabric, which are: La Sagrada Familia Church (4.5 million visitors), Gul Park (3.1 million visitors), Casa Batllo (1.1 million visitors), and finally, La Pedrera (900,000 visitors). Barcelona's tourism plan strategy relies on this central axis existing with other axes in the city's development. Therefore, the works of Gaudi are among the pillars of the city's tourism plan. A guiding system (Wayfinding) done inside the city indicates to the visitor the sites of Gaudi's works, inside the urban fabric. This strategy depends on the following:

1. Preserving the heritage sites inside Barcelona and its importance as a civilized and cultural source for the Spanish-Catalan conflict and for proving identity, these buildings transferred to become open museums for tourists.

2. Use of these sites to gain economic return, as most Gaudi-related works or designs have entry fees ranging from 20-40 Euros (equivalent to 80-160 Saudi riyals per visit).

3. Distributing the touristic tour of Gaudi's works so that it links the parts of the city, which in turn revives the areas around each site, such as residential hotels, cafes, restaurants, markets and retail stores. It is considered a comprehensive development that takes into account all the components of the city, its essential elements, and it encourages the market and local society.

4. More than five sites were registered in UNESCO, to confirm the authenticity of the city's identity, which gives momentum to these sites, placing them on the global tourism map and ensuring their continuity; in terms of financial, technical and other forms of support.

\subsection{London, UK: Zone 1}

The city of London, considered one of the largest capitals in the world, has a large number of heritage sites that are not less than 300 years old, distributed among buildings on a small scale within the borders of the old city (Zone 1). London is the most popular tourist destination in the whole world, attracting about 30 million visitors from other countries every year [27]. People travel to London from every corner of the globe to admire the many impressive monuments in London, explore the vibrant culture in the city, and perhaps participate in a theatrical performance or celebrate Victorian art [27]. These built heritage sites symbolize several different eras, some were built in the Victorian era and some others during the Renaissance. Their forms differ, as there are public buildings, palaces, churches, gardens, public squares and many others. Most of these sites are located on the banks of the River Thames randomly, without linking, so then the City of London has undertaken a strategy to support the private sector, to make a tourist path for public transport buses and tourist buses, to activate and link sites, to excite the visitor to London.

Income from tourism in London accounts for about $10 \%$ of the city's total added value income: Tourists in London are expected to spend around 15 million pounds annually. This figure includes all aspects of industry, and about $13 \%$ of the city's population works in this tourism sector, in one form or another [27].

In London, the notion of conserving the urban heritage as a development and tourism resource in the city depends on the following: 
1. Preserving the English identity within the heritage sites, in terms of the nature of the construction and the authentic urban fabric that dates back hundreds of years.

2. Linking the heritage sites with each other by tourist paths that are supported by the city's municipality, and operated by the private sector, to promote the idea of having a "living heritage".

3. Advertising and promotional campaigns through partnerships between residence issuance offices in the UK, in terms of promoting heritage/tourism sites within the city of London and promoting the city as a global commercial product.

4. Exploiting heritage sites by stimulating tourism, by safeguarding the heritage sites and transferring to them new functions, such as having offices, shopping malls, museums and more available.

5. Benefitting from heritage sites to perform cultural and artistic activities, by changing the use of these sites, such as changing some sites to become hotels or cafes.

6. Registration of some sites with UNESCO, to promote tourism and to create international support through financial and technical support work.

7. At least $10 \%$ of the city's population is employed in the tourism sector.

In conclusion, the two above examples consider that one of the best approaches is to reuse the built heritage sites to allot new functions that can support the idea of heritage tourism or living heritage. This approach helps to support the local economy, create jobs and most importantly, to conserve the heritage site and the identity of the city.

\section{MAKKAH'S BUILT HERITAGE SITES AND TOURISM}

\subsection{City of Makkah}

The holy city of Makkah (or Mecca) is considered by the Muslims to be the most important spiritual city, which is also called the Holy City. The city, located in the western region of Saudi Arabia with less than 2 million in population, is distinguished as a destination for millions of Muslims every year, to perform Hajj or Umrah [28]. Makkah is forbidden for non-Muslims to enter it, due to religious obligations. Therefore, the kind of tourism approach that will be applicable for Makkah is "religious tourism".

\subsection{Built heritage sites in Makkah}

A survey conducted by the author took place from November 2019 to January 2020, to visit the existing heritage sites. This has shown that Makkah still has few built heritage sites. The purpose of this survey was to identify, observe and analyze the existing built heritage sites in Makkah. This work was based on a recent survey done in 2019 by Makkah Municipality, which identified 51 heritage sites in Makkah Province, inside and outside the city boundary (Figs 1 and 2). The Municipality survey included all kinds of heritage, not only the built ones (for example, it included ancient wells, ponds and antiquities).

The author overlapped the two surveys based on the following criteria:

- The site has to be tangible (built heritage site).

- The site has to be located inside the city boundary.

- The site has to have significant importance at different levels: internationally (i.e. for Muslim nations), nationally and locally.

- The site has to be in at least a fair physical condition, that will be able to support the idea of becoming tourism heritage. 


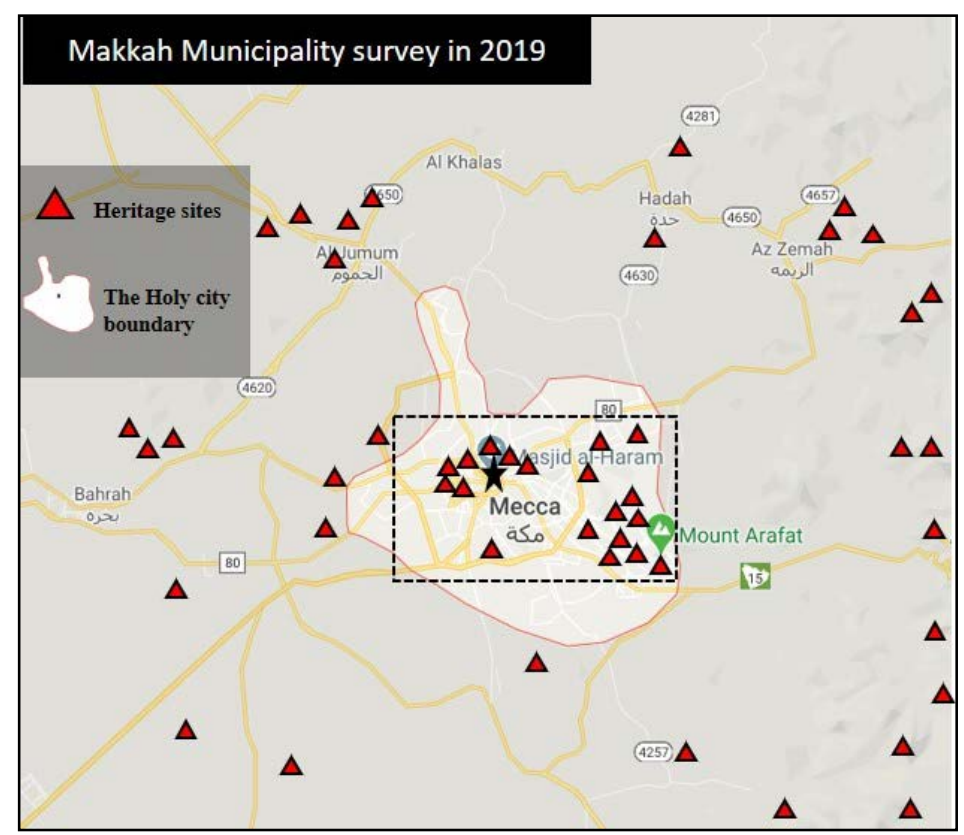

Figure 1: Makkah municipality: Survey of all heritage sites in Makkah, 2019.

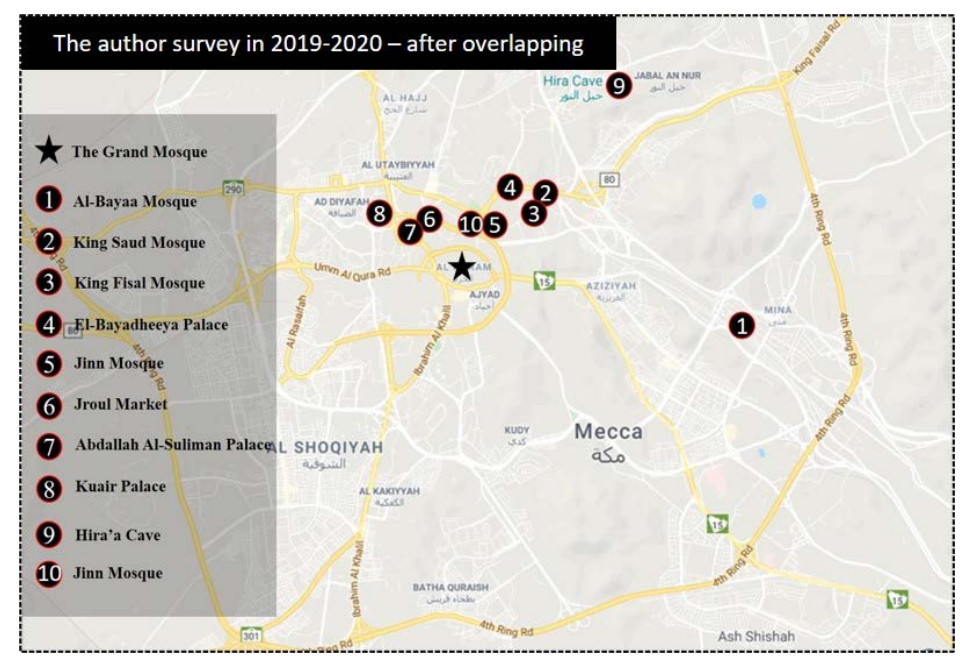

Figure 2: The author's 2020 survey to find the built heritage sites in Makkah.

The results of this filtration indicated that there are 10 sites (three mosques, five palaces, one market and one religious site) that can be developed for tourism. The author excluded the mosques, for religious reasons; however, the author visited these sites and conducted observations of their authenticity, physical conditions, their level of importance and historical background (Table 1). The result of this observation was that most of the seven remaining 


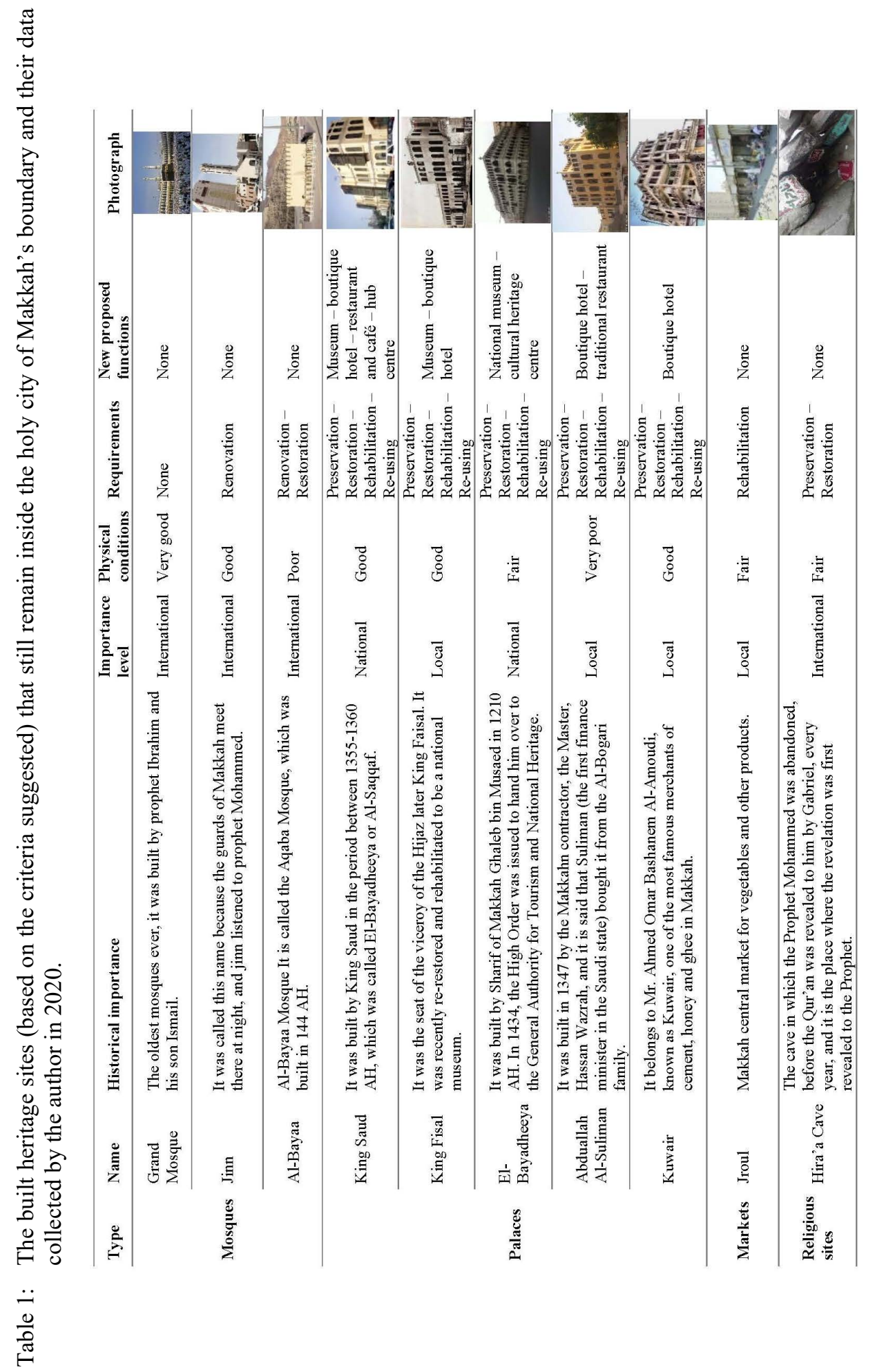


sites have the potential to be developed as individual monuments, due to their location within the city's urban fabric. Most of the chosen sites were at least 70 years old, because most of the built heritage sites have been demolished around the Grand Mosque, during expansion projects in the last few decades. On the other hand, these are the last remaining built heritage sites in the holy city of Makkah.

Table 1 illustrates that most of the palaces $(60 \%)$ are in a reasonable physical condition, have local and national importance, and all of them require multiple development actions (such as preservation, restoration, and more). Moreover, new functions have been proposed for these sites; for example, the author suggested transferring Kuwair Palace into a boutique hotel, based on the site visit, observations and analyses.

\subsection{Tourism in Makkah}

As mentioned previously, the tourism type for Makkah is religious tourism. This industry is related to the Grand Mosque and the other religious sites during the Umrah and Hajj seasons. The idea of heritage tourism was never been introduced to the local authorities in its modern definition, until the Kingdom Vision 2030 was introduced in 2015. Now a new program called "Hajj and Umrah Vision Realization Program" has been launched, with the collaboration of different stakeholders to upgrade the journey of pilgrims. This program aims to enrich the pilgrims' experiences in general, and it indicates the importance of "developing the world's tourism and cultural sites" [29]. Resulting from that, some local initiatives by local investors and governmental agencies were founded in Makkah.

For instance, the Alamoudi Museum (Fig. 3) is attempting to document some of Makkah and Saudi costumes, and our cultural collaboration with some Umrah and Hajj companies, which are considered tourist agencies. This museum might be one of few heritage journeys that are offered to pilgrims in terms of the idea of heritage tourism, but it is essential to mention that these sites are not part of the heritage sites in the city. Also, there are some public museums and exhibitions created by government agencies, such as the Clock Tower Museum, Mecca Museum and Assalamu Alaika Ayyuha Annabi Museum.

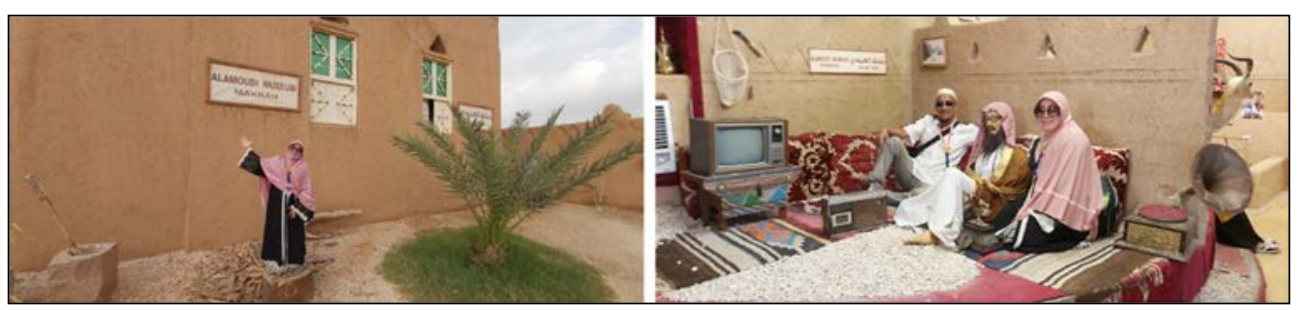

Figure 3: Alamoudi Museum in 2019, during one visit of pilgrims.

\subsection{Kuwair Palace}

The abandoned Kuwair Palace was built by Ahmad Bashnem Alamoudi, also known as Kuwair, and the palace was designed by an unknown Turkish architect. Built in $1370 \mathrm{AH}$ (around 1951 AD), it is located in the El-Byban district. Residents occupied the house till 2011. It is distinguished for its location close to the Grand Mosque (Al-Haram or Masjid alHaram) on the main road into the city (Fig. 4), with its privileged location on a small hill. 

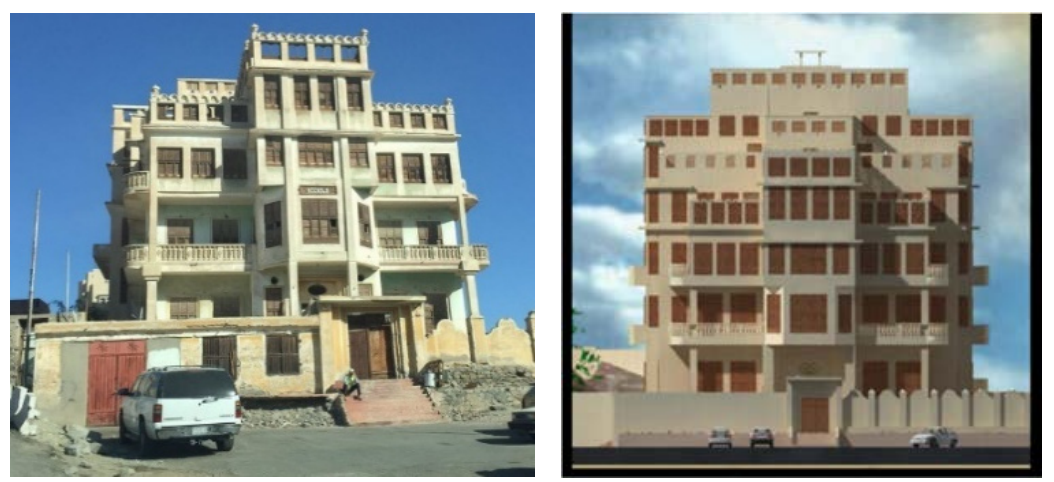

Figure 4: The facade of Kuwair palace. The picture on the right is documentation done by Islamic Architecture Department students in 2012 and the photograph on the left is an updated shot by the author in 2020 .

The architectural style of the palace is a mixture between the traditional Hejazi architecture and Art Deco architecture, and this might go back to the origin of the architect (Fig. 4). The place was built by using local stones (Shubykah stones) that are supported by wooden beams covered by plaster (locally called Noura). Additionally, the palace consists of more than 40 rooms, distributed over its five stories (the fifth floor is considered a roof). It contains a Kharyjah (terrace), a place where the people of the house sleep in the summer period. The lower floors (the ground, the first and the second floors) that are separated as guest rooms, and the upper floors (the third, the fourth and the fifth floors) are reserved for the people of the house, for privacy. The kitchen is located on the fifth floor, for natural ventilation. A staircase that connects all these floors with that is uniquely designed, as is the main water tank, distributed from it to all the floors of the palace, and visitors can see the tanks (Fig. 5).

The palace is famous for its unique façade design, as it symbolizes Makkah's architecture through Islamic windows (mashrabiyas) and ornaments with some Art Deco elements, such as the small balconies (Fig. 6). There are many mashrabiyas to provide natural ventilation and light. This description was for the exterior, but the interior was designed to accommodate family needs, providing privacy and comfort. Despite its apparent deterioration due to abandonment, the palace is still in excellent physical condition; and would just need further restoration, renovation and rehabilitation in order to be ready for any touristic development. Many lighting elements, decorative elements, woodwork, tiles and doors are found in their original state (Fig. 6).

The author claims that Kuwair Palace can be restored, renovated, rehabilitated and then re-used as a boutique, vintage hotel, due to its location close to the Grand Mosque, architectural identity and its typology. The palace can be divided up into several suites, each suite served by a bedroom, toilet and shower, kitchenette, sitting area and terrace; with a shared dining room offering traditional meals (Fig. 7). The ground floor can be allocated for a lobby and guest services. A shuttle bus could be used for transportation from the palace to the Grand Mosque. Through this approach, the palace would be conserved and developed in a new tourism approach that would create jobs for locals (hotel staff, local chefs for traditional meals, local artisans and more) and support the local economy. This approach can also be implemented in the other built heritage sites with different functions given based on the location, physical conditions and architectural style of these sites (Table 1). 


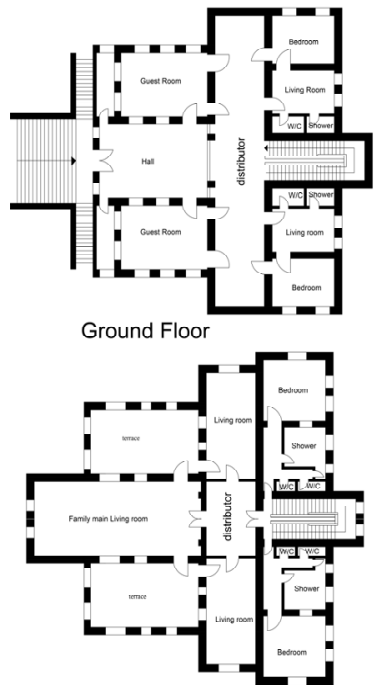

3rd Floor
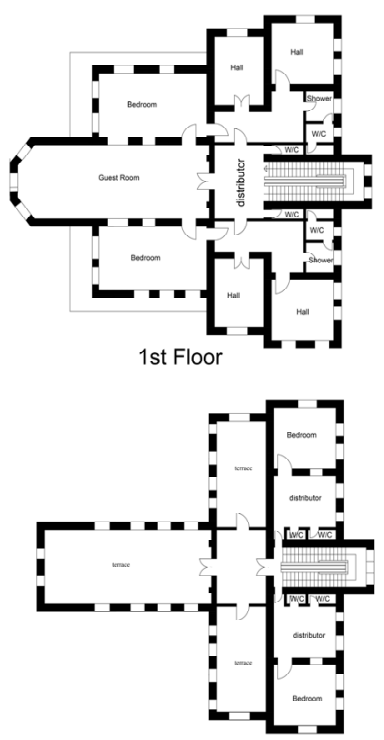

4th Floor
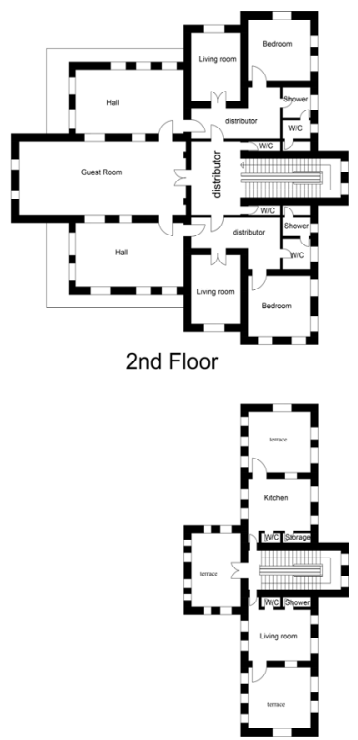

5th Floor

Figure 5: The typology of Kuwair Palace, done by Islamic Architecture Department students in 2012. (Source: Updated by the author in 2020.)
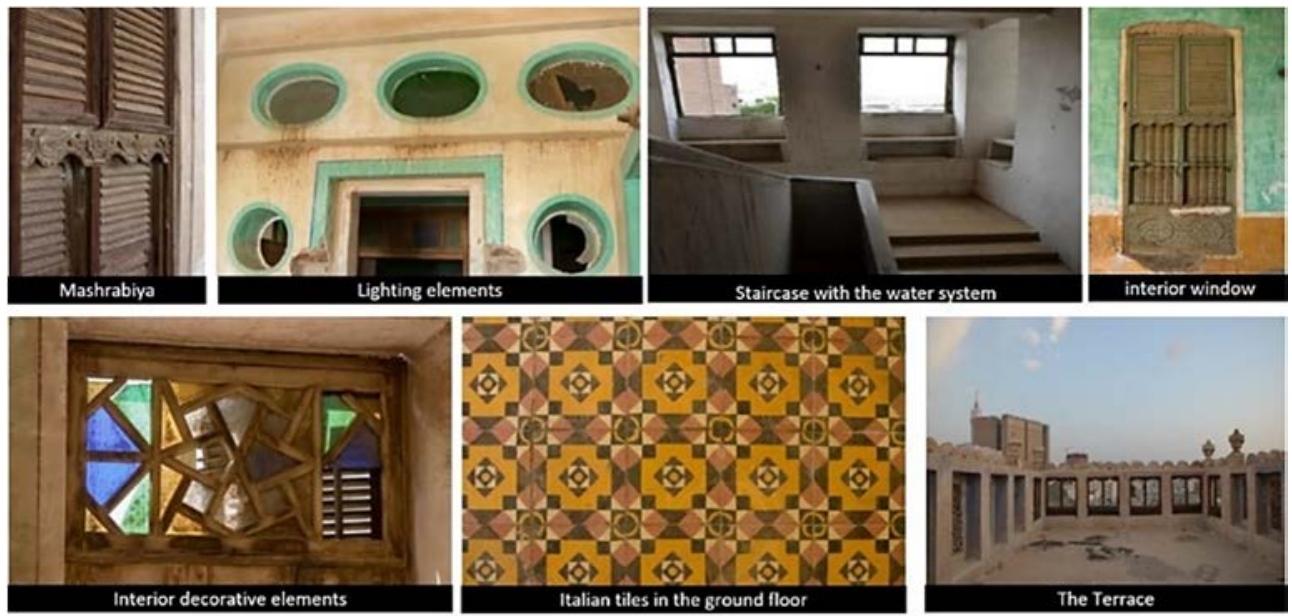

Figure 6: Some decorative elements in the interior of Kuwair palace, 2020. (Source: The author.)

\section{CONCLUSIONS}

This paper illustrates the literature on built heritage conservation and tourism from a different perspective. It shows the strong relationship between the two concepts; and how they support each other spontaneously, with some few concerns, especially in the negative physical 


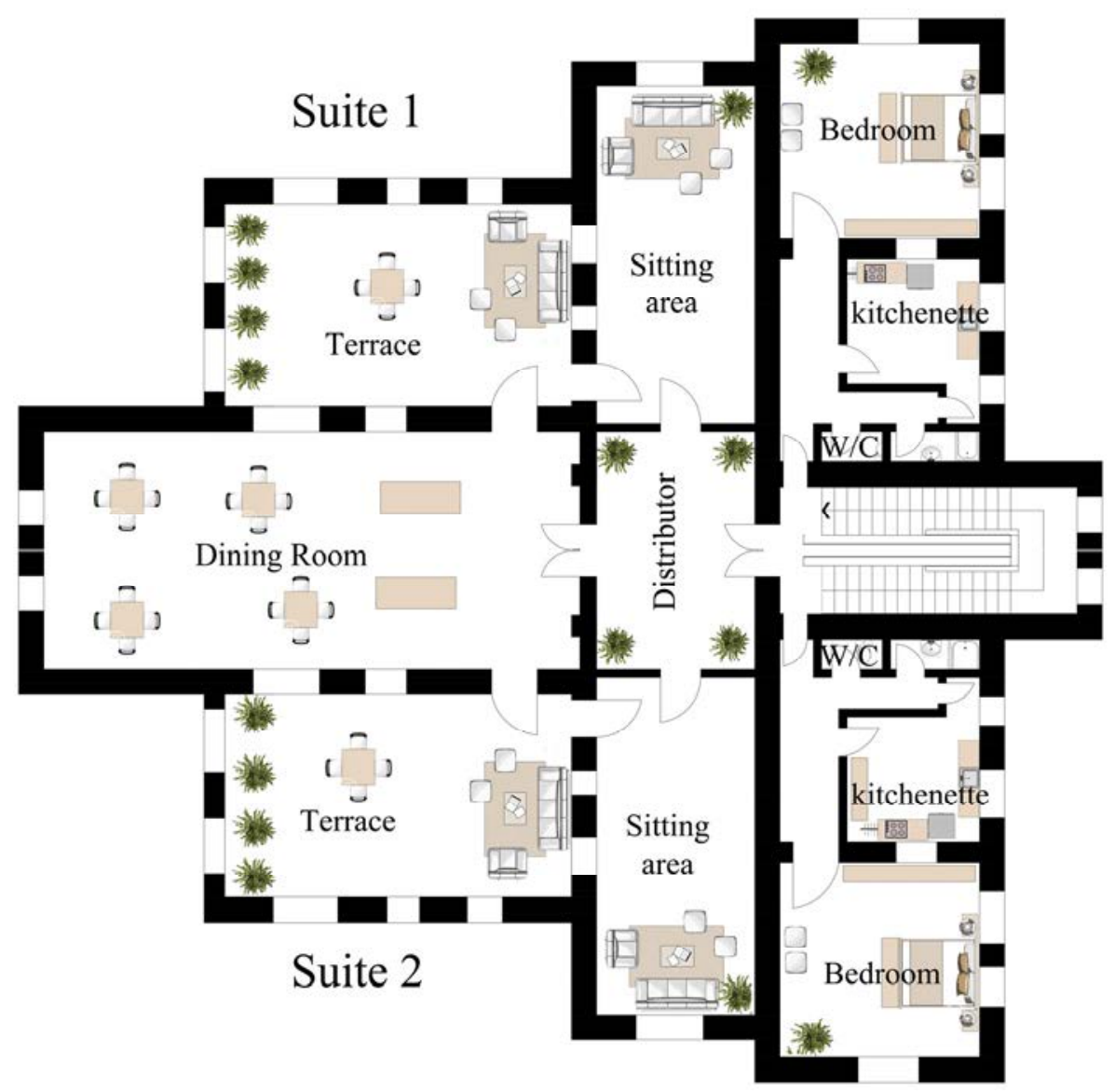

Figure 7: The proposed new functions for Kuwair Palace. (Source: The author.)

impacts of tourism on built heritage sites. Different examples were illustrated, in order to show different nation's approaches in dealing with heritage sites and tourism. No doubt that tourism can play a constructive role in conserving built heritage sites; due to economic, cultural and social effects. The holy city of Makkah has chosen to implement this approach; however, the city has lost many built heritage sites for adjustment reasons such as "expansion of the Grand Mosque and its surroundings", to embrace millions of pilgrims every year. The paper presented different built heritage sites that still exist in Makkah, which need urgent attention and development. Kuwair Palace is an example of how tourism can become an essential tool to help conserve Makkah's built heritage sites, via re-use of these sites for a new function that is aligned with the present requirements and the new vision of the country.

\section{ACKNOWLEDGEMENTS}

The author would like to thank Makkah Municipality's Heritage Unit for their support, by providing recent data about heritage sites in Makkah. Also, the author would like to thank the Islamic Architecture Department at Umm Al-Qura University, for providing documentation on Kuwair Palace. 


\section{REFERENCES}

[1] UNESCO, Managing the World's Cultural Heritage, 2016. (In Arabic.)

[2] Rahman, S., Heritage tourism and the built environment. PhD thesis, University of Birmingham, UK, 2012.

[3] Behiri, A., Heritage rehabilitation in sustainable development policy for a better environment quality in small historical coastal cities: The case of Cherchell in Algeria. International Conference on Green Buildings and Sustainable Cities, pp. 753-759, 2011.

[4] Graham, B., Sharing space? Geography and politics in post-conflict Northern Ireland. Cultural Memories: The Geographical Point of View, Springer Dordrecht: Heidelberg, London, New York. 2011.

[5] Adongo, R., Choe, J.Y. \& Han, H., Tourism in Hoi An, Vietnam: Impacts, perceived benefits, community attachment and support for tourism development. International Journal of Tourism Sciences, 17(2), pp. 86-106, 2017.

[6] Bagader, M., The evolution of built heritage conservation policies in Saudi Arabia: Historic Jeddah as a case study. PhD thesis, University of Manchester, UK, 2016.

[7] Kuban, D., Conservation of the historical environment for cultural survival. Conservation as Cultural Survival, Istanbul: The Aga Khan Award for Architecture, ed. R. Holod, 1978.

[8] Andrews, S., Introduction to Tourism and Hospitality Industry, Tata McGraw-Hill: New Delhi, 2011.

[9] World Tourism Organization (UNWTO), Sustainable development. www.unwto.org.

[10] Van Zyl, C., The role of tourism in conservation of cultural heritage with particular relevance for South Africa. PhD thesis, University of Stellenbosch, 2005.

[11] Graham, B. \& Howard P. (eds.), The Ashgate Research Companion to Heritage and Identity, Ashgate: Aldershot, 2008.

[12] McKercher, B. \& Ho, P.S.Y., Assessing the tourism potential of smaller cultural and heritage attractions. Journal of Sustainable Tourism, 14(5), pp. 473-488, 2006.

[13] Avrami, E., Mason R. \& Torre, M. (eds.), Values and Heritage Conservation, Getty Conservation Institute: Los Angeles, 2000.

[14] Orbaşli, A., Conservation training in the Middle East. Built Environment, 33(3), pp. 307-322, 2007.

[15] Kousis, M., Tourism and the environment: A social movements perspective. Annals of Tourism Research, 27(2), pp. 468-489, 2000.

[16] Gibson, J., Preservation Glossary Today's Word: Heritage Tourism, The National Trust for Historic Preservation, 2015.

[17] Cros, du H., A new model to assist in planning for sustainable cultural heritage tourism. International Journal of Tourism Research, 3, pp. 165-170, 2001.

[18] Orbaşli, A. \& Woodward, S., Tourism and heritage conservation. Handbook of Tourism Studies, eds T. Jamal \& M. Robison, Sage: London, 2009.

[19] Rosenfeld, R., Cultural and heritage tourism. Municipal Economic Development Tool Kit, 2008.

[20] World Tourism Organization (UNWTO), Charter for Sustainable Tourism, UNWTO: Madrid, 1995.

[21] Chaudhry, M., Approaches to Tourism Development, University of Delhi: New Delhi, 2010.

[22] Rogers, P., Conservation and implementation. Conservation of Buildings in Developing Countries, ed. R. Zetter, Oxford Polytechnic: Oxford, 1982. 
[23] Rothman, H., Devil's bargains: Tourism in the twentieth-century American west. Development of Western Resources, 2000.

[24] ICOMOS, Tourism at World Heritage Cultural Sites, World Tourism Organization, 2004.

[25] UNESCO Venice Office, Culture and development in Venice: From restoration to revitalisation? The future of Venice, Report number 3, 2011.

[26] Statista, The most visited sites in Barcelona. www.statista.com/. Accessed on: Feb. 2020.

[27] London's economic plan and major industries. www.uncsbrp.org/tourism.htm/. Accessed on: Jan. 2020.

[28] Saudi General Authority for Statistics, Hajj and Umrah surveys in 2019. www.stats.gov.sa/. Accessed on: Apr. 2020.

[29] Saudi Arabia Government, Hajj and Umrah vision realization program. Saudi Vision 2030. https://vision2030.gov.sa/en/programs/Hajj-and-Omrah. Accessed on: Apr. 2020 . 